\title{
Communication
}

\section{Urbanization and Inequality/Poverty}

\author{
Brantley Liddle \\ Energy Studies Institute, National University of Singapore, Singapore 119620, Singapore; \\ btliddle@alum.mit.edu; Tel.: +65-6516-7080
}

Received: 22 September 2017; Accepted: 24 November 2017; Published: 27 November 2017

\begin{abstract}
The level of world urbanization has crossed the 50\% mark, and nearly all future population growth is projected to occur in cities. Cities are disproportionately wealthy, but are associated with poverty, too. Addressing the dual challenges of urbanization and poverty is key to achieving sustainable development. This paper performs cross-sectional regressions, based on Kuznets, as a starting point for understanding the relationship between urbanization and poverty/inequality indicators. Increases in gross domestic product per capita unambiguously lowered poverty and narrowed rural-urban gaps. By contrast, levels of urbanization were either unrelated to poverty/inequality indicators and measures of rural-urban gaps, or had a nonlinear effect where, initially, increases in urbanization likewise led to improvements in those areas, while at higher levels of urbanization, increases in urbanization exacerbated poverty and rural-urban gaps.
\end{abstract}

Keywords: economic growth and urbanization; urbanization and inequality/poverty; Kuznetstype relationships

\section{Introduction}

World urbanization exceeded $50 \%$ for the first time in 2009. According to the United Nations, urban areas will absorb all of the projected 2.5 billion global population growth and continue to draw in some rural population over the next 40 years [1]. Additionally, less developed regions will account for most of the population growth expected in urban areas. While the impact of urbanization on the environment has been studied (e.g., see [2] for a review), understanding regarding the poverty-urbanization relationship is lacking [3]. Yet, those two forces-poverty and urbanization-are apparent causes for the lack of achieving sustainable development [3]. In Kuznets' [4] well-known paper, he demonstrated that there is an inverted U-shaped relationship between income inequality and economic growth, i.e., as countries initially get wealthier, inequality increases, but at some sufficiently high level of wealth/development, further increases in wealth correspond to lower levels of inequality. This short communication uses a simple model that is based on Kuznets' seminal work as a starting point to analyze the impact of urbanization on several measures of both poverty and inequality.

\section{Background}

Liddle [5] - in an analysis that considered city-based data from three datasets [6-8]; a total of 167 cities - calculated the ratio of a city's gross domestic product (GDP) per capita to the associated country GDP per capita. GDP per capita is higher for most cities than for their respective countries as a whole- the ratio of city-to-country GDPs is less than one for only 35 cities, and less than 0.85 for only 14 [5]. Furthermore, the relative economic importance of cities is stronger in countries with lower GDP per capita [5]. That second point (i) illustrates that cities in developing countries exercise an important migratory pull; and (ii) helps explain that urban areas will be the locus of all UN projected future population growth (over the next 40 years). Indeed, rural-urban migration accounts for around half of the total urban population in Africa [9]. 
Urbanization and economic development do tend to accompany one another; in part, this is because the industrialization process involves the agricultural labor force migrating from rural farms to urban manufacturing plants. However, slow economic growth has spurred rural-urban migration and led to the phenomenon of urbanization without growth, particularly in Africa [10-13]. Similarly, in the case of India, how fast a state urbanizes is negatively correlated with that state's rate of economic growth [14]. Ultimately, urbanization may be more evidence of economic progress than a catalyst for economic growth, and the/any relationship between urbanization and development may be an equilibrium one [13,15].

Table 1 displays data from the World Bank's World Development Indicators database [16] on various measures of urban poverty and rural-urban differences. Data were collected for all countries not classified as high-income by the World Bank (this meant a maximum of 137 countries, but not all countries have data for each variable). For data that are collected annually, the most recent year was used (typically either 2014 or 2012); for data that are less frequently collected, the average over 2010-2014 was used.

Table 1. Descriptive statistics for urban poverty indicators and rural-urban poverty comparisons. Non-high-income countries.

\begin{tabular}{ccccccc}
\hline Indicator & Mean & Median & Maximum & Minimum & Std. Dev. & X-Sects. \\
\hline Urban electricity access & 84.1 & 98.1 & 100 & 12.3 & 22.1 & 137 \\
Rural-urban electricity ratio & 0.62 & 0.71 & 1.00 & 0.02 & 0.35 & 137 \\
Urban water access & 93.4 & 96.7 & 100 & 58.4 & 8.3 & 131 \\
Rural-urban water ratio & 0.83 & 0.89 & 1.04 & 0.37 & 0.17 & 128 \\
Urban poverty share & 23.0 & 20.3 & 61.6 & 0.65 & 14.5 & 68 \\
Rural-urban poverty share ratio & 2.34 & 1.95 & 9.28 & 0.99 & 1.51 & 67 \\
Urban slum share & 46.1 & 46.2 & 95.6 & 5.5 & 23.7 & 82 \\
\hline
\end{tabular}

Std. Dev. = Standard Deviation, X-Sects. = cross-sections. Note: Observations taken from 2010 to 2014 [16].

The data do suggest that people in cities tend to have more opportunities than people in rural areas (since people in urban areas likely have more access to resources-electricity, quality water, education, health care, transport, capital, culture/arts-than do people in rural areas, and since access to such resources tends to increase opportunities for quality of life). Nearly all urban dwellers have access to electricity and quality water (the median shares of urban dwellers with such access are $98 \%$ and $97 \%$, respectively). The ratio of the rural to the urban share of population with access to electricity/water demonstrates that urban dwellers are more likely to have such access than their rural counterparts. The median ratios are 0.71 and 0.89 for electricity and water, respectively, suggesting the urban population is about $10-30 \%$ more likely to have such access.

However, there is poverty in urban areas, too; almost half of urban populations live in settlements defined as slums (the World Bank defines a slum as a house that lacks one or more of the following conditions: access to improved water, access to improved sanitation, sufficient living area, and durability of housing). Moreover, over a fifth of the urban population lives below their national poverty lines. Yet, the share of people living below the poverty line in rural areas is double that, since the median ratio of rural-to-urban poverty share is 2 .

\section{Analysis and Discussion}

Initially, we revisit Kuznets' analysis by also considering urbanization levels via cross-sectional regressions. Cross-country data is particularly useful in studying developmental change; such data allow for the greatest degree of generalization, and are in the spirit of Kuznets' original analysis. We perform pure cross-sectional regressions (in Tables 2-4), since the measurements of the dependent variables differ much more across countries than across time. Furthermore, a cross-section is more appropriate when including nonlinear transformations of variables, since using pure cross-sectional 
data avoids the statistical complications that arise when such operations are performed on time-series data (see e.g., $[17,18])$.

Specifically, we use the Gini index as the measure of inequality, and estimate it (i) as a nonlinear function of GDP per capita (in constant 2011 international dollars that are adjusted for purchasing power parity); and (ii) as a nonlinear function of urbanization. The Gini index is based on the Lorenz curve, which plots the proportion of total income of a population that is cumulatively earned by the bottom $\mathrm{x} \%$ of the population. So, a 45 degree line represents perfect equality of incomes, and the Gini index is the ratio of the area that lies between the 45 degree line and the Lorenz curve. Hence, a Gini index of 0 represents perfect equality.

The data are from the World Bank's World Development Indicators [16], and the observations are from 2013 for GDP per capita and urbanization and from the average over 2007-2013 for the Gini index (which is stable over time, and, for many countries, is observed/recorded only occasionally). All variables have been converted to natural logs so that their estimated coefficients can be interpreted as elasticities. The cross-section contains 133 countries (which include high-income countries), and the regression results are displayed in Table 2.

Table 2. Kuznets-style cross-sectional regression. GINI index is dependent variable.

\begin{tabular}{cc}
\hline Independent Variables & \\
\hline GDP per capita & $0.60 * * *(0.20)$ \\
GDP per capita squared & $-0.04^{* * *}(0.01)$ \\
Urbanization & $-0.81^{*}(0.45)$ \\
Urbanization squared & $0.13^{* *}(0.06)$ \\
\hline Adjusted $R^{2}$ & 0.20 \\
Observations & 133 \\
Turning points & \\
GDP per capita & US\$1711 \\
Urbanization & $23 \%$ \\
\hline
\end{tabular}

GDP = gross domestic product. Notes: All variables in natural logs. White-heteroskedasticity-consistent standard errors in parentheses. Statistical significance is indicated by: ${ }^{* *} p<0.01,{ }^{* *} p<0.05$, and ${ }^{*} p<0.1$ [16].

For the polynomial model considered here, an inverted-U relationship between the dependent and independent variables is said to exist if the coefficient for the linear term, $\beta_{1}$, is statistically significant and positive, while the coefficient for the squared term, $\beta_{2}$, is statistically significant and negative. Moreover, whenever the estimations suggest a parabolic relationship (i.e., one coefficient is positive and the other negative), the implied turning point, $\tau$-or the level of the independent variable at which the sign of the relationship between dependent and independent variable changes—can be calculated by:

$$
\tau=\exp \left(-\beta_{1} /\left(2 \beta_{2}\right)\right)
$$

The regression confirms the expected inverted-U relationship between income inequality and income. The turning point of under US $\$ 2000$ per capita is well within the sample range-indeed, the mean income is over US\$14,500, and the median is over US\$9300. Interestingly, urbanization has a U-shaped relationship with inequality, i.e., initially, increases in urbanization are associated with lower levels of inequality, but ultimately, increases in urbanization are associated with higher levels of inequality. Again, the estimated turning point of $23 \%$ urbanization is well within the sample range; both the mean and median levels of urbanization are around $55 \%$. This finding that higher urbanization can lead to more inequality in a cross-sectional context echoes the results of a recent, time-series-based, China-only study [19].

Next, we revisit the variables on urban poverty and rural-urban differences introduced in Table 1 to determine whether/how the level of income or urbanization is associated with those indicators via cross-sectional regressions (income and urbanization data are the same as described above). As before, the variables have been converted to natural logs so that their estimated coefficients can be interpreted 
as elasticities. We believe that income should improve these measures monotonically, so we do not consider a polynomial of GDP per capita. However, we do allow for a possible nonlinear relationship with urbanization level (urbanization squared was usually insignificant, and only significant results for this transformation are shown in the table). The regression results are displayed in Table 3.

Table 3. Cross-sectional regressions of the effects of GDP per capita and urbanization on urban poverty indicators and rural-urban poverty comparisons.

\begin{tabular}{|c|c|c|c|c|c|c|}
\hline Regression & I & II & III & IV & $\mathbf{V}$ & VI \\
\hline $\begin{array}{c}\text { Dependent } \\
\text { Variable }\end{array}$ & $\begin{array}{l}\text { Urban } \\
\text { Electricity } \\
\text { Access }\end{array}$ & $\begin{array}{l}\text { Rural-Urban } \\
\text { Electricity } \\
\text { Ratio }\end{array}$ & $\begin{array}{c}\text { Urban } \\
\text { Poverty } \\
\text { Gap }\end{array}$ & $\begin{array}{c}\text { Urban } \\
\text { Poverty } \\
\text { Share }\end{array}$ & $\begin{array}{c}\text { Rural-Urban } \\
\text { Poverty } \\
\text { Share Ratio }\end{array}$ & $\begin{array}{l}\text { Urban } \\
\text { Slum } \\
\text { Share }\end{array}$ \\
\hline GDP per capita & $\begin{array}{c}0.28 * * * \\
(0.05)\end{array}$ & $\begin{array}{c}0.67^{* * *} \\
(0.10)\end{array}$ & $\begin{array}{c}-1.19 * * * \\
(0.17)\end{array}$ & $\begin{array}{c}-0.90^{* * *} \\
(0.13)\end{array}$ & $\begin{array}{l}0.19 \text { ** } \\
(0.07)\end{array}$ & $\begin{array}{c}-0.42^{* * *} \\
(0.09)\end{array}$ \\
\hline Urbanization & $\begin{array}{l}-0.08 \\
(0.09)\end{array}$ & $\begin{array}{l}3.29 * \\
(1.83)\end{array}$ & $\begin{array}{l}-5.87^{* *} \\
(2.34)\end{array}$ & $\begin{array}{c}1.17^{* * *} \\
(0.18)\end{array}$ & $\begin{array}{c}-0.39 * * * \\
(0.13)\end{array}$ & $\begin{array}{l}-0.19 \\
(0.15)\end{array}$ \\
\hline $\begin{array}{l}\text { Urbanization } \\
\text { squared }\end{array}$ & & $\begin{array}{c}-0.42 * \\
(0.25)\end{array}$ & $\begin{array}{l}1.08^{* * *} \\
(0.36)\end{array}$ & & & \\
\hline Adjusted $\mathrm{R}^{2}$ & 0.39 & 0.52 & 0.43 & 0.41 & 0.07 & 0.47 \\
\hline Observations & 128 & 128 & 47 & 67 & 66 & 78 \\
\hline Turning point & & $49 \%$ & $15 \%$ & & & \\
\hline
\end{tabular}

For the share of urban population with electricity access and the share of urban population living in slums (i.e., Regressions I and VI), GDP per capita had the expected, statistically significant impact. For urban electricity access, a one \% increase in GDP per capita leads to a $0.3 \%$ increase in access; whereas, for urban slum share, a one \% increase in GDP per capita leads to a $0.4 \%$ fall in the share of people living in slums. For both of those regressions, the level of urbanization was insignificant. For the rural-to-urban share of people living in poverty (i.e., Regression V), both income and urbanization were statistically significant, but the associated R-squared for the regression was very low, i.e., the model had a poor fit.

Urbanization had a more interesting relationship for the other dependent variables. For example, for the rural-to-urban electricity access ratio (i.e., Regression II), urbanization had an inverted-U relationship. A one \% increase in GDP per capita raised the ratio by two-thirds of a percent-i.e., the rural-urban electricity access gap narrows at higher income. Initially, higher urbanization levels are associated with a higher access ratio/narrower gap as well, but at urbanization of 49\%-approximately the mean and median for the 128-country sample-higher levels of urbanization are associated with a lower access ratio/larger rural-urban gap (i.e., disproportionately less electricity access for rural populations). In other words, at higher levels of urbanization, rural populations are more likely to be "left behind." Perhaps, at high levels of urbanization, there is less interest/incentive for governments to invest in rural infrastructure.

The urban poverty gap regression (Regression III) reveals a similar nonlinear relationship with respect to urbanization. The urban poverty gap is the urban population's mean shortfall from the poverty lines (counting the nonpoor as having zero shortfall) as a percentage of the poverty lines-so the measure reflects the depth of poverty and its incidence. Again, not surprisingly, GDP per capita has a strong negative relationship; indeed, increases in GDP per capita reduce this gap more than proportionally. Urbanization now has a U-shaped relationship with the urban poverty gap; however, because of the definition of the dependent variable, the basic relationship is the same as with the rural-to-urban electricity access ratio, i.e., initially, increases in urbanization are associated with 
an improvement (i.e., lower urban poverty gap), but ultimately, urbanization is correlated with a worsening in poverty.

What is particularly surprising about Regression III is the relatively low turning point for urbanization; indeed, the turning point is only 15\%, whereas, the mean/median is approximately $40 \%$. It is possible that when urbanization increases because of rural to urban migration, those rural migrants settle in marginal urban areas so that urban poverty increases. However, one should be mindful of the relatively small sample size of Regression III (only 47 out of 128 countries had the urban poverty gap data). Moreover, those countries included in Regression III were disproportionately poorer than the "full sample" (of Regressions I and II). For example, the mean and median GDP per capita for Regression III were only US\$5200 and US\$3600, respectively, compared to US\$8000 and US\$6500, respectively, for the 128-country sample (Regressions I and II). Moreover still, the maximum GDP per capita for Regression III was approximately US\$14,500, which means the 21 richest countries in the 128-country sample were not included. By contrast, the range of urbanization levels is similar for the smaller sample (Regression III) and the larger ones (e.g., Regression I): 12-78\% compared to $12-89 \%$, respectively.

The urban poverty share regression (Regression IV) is similar to the urban poverty gap regression (Regression III) in two ways: (i) the smaller sample of countries are poorer than the larger sample-mean and median GDP per capita are US\$6600 and US\$4700, respectively; and (ii) increases in urbanization seem to offset improvements from increases in GDP per capita. Indeed, increases in GDP per capita lower the share of urban population living in poverty by nearly one-to-one; however, increases in urbanization appear to more than offset that improvement in poverty reduction (urbanization's elasticity is 1.2). Again, the results could be interpreted as suggesting that, when urbanization increases because of rural to urban migration, poverty among the (newly designated) urban population would increase as well. Indeed, there is evidence that rapid urbanization has caused worsening urban poverty (e.g., [20]) — a finding that is in concert with both Regressions III and IV.

Lastly, we consider another method for analyzing potential nonlinearities, i.e., the quantile regression (initially proposed by [21]). A quantile regression estimates the linear relationship between regressors and a specified quantile of the dependent variable (in this example we use quartiles). Among the questions quantile regressions can address are: (i) whether the coefficient estimates vary across different quantiles of the dependent variable; and (ii) whether the coefficients for the median are statistically different from those estimated at the upper and lower quantile.

The quantile regressions typically suggest a uniform impact of urbanization (see Table 4). The main exception to that result is for the Gini index, for which urbanization is significant only at the higher quantiles of the index, i.e., urbanization matters in societies that are the most unequal. There was more evidence of differences across quantiles for income - this was the case for nearly half of the dependent variables as displayed in Table 4 (results for the other quantile regressions not shown, but are available upon request).

The impact of GDP per capita declines significantly when the share of urban population with electricity access is sorted by quartiles (consider the reported $p$-value of the slope equality test between the lower and median quartile and between the upper and median quartile)_an unsurprising saturation effect. A similar pattern is observed for both the rural-to-urban electricity access ratio and the urban poverty share; however, the difference between estimations is only statistically significant when comparing the median quartile with the top quartile. For the rural-to-urban electricity access ratio, that relationship is in concert with the same finding for urban electricity access, as would be expected. Whereas, for the urban poverty share, the quantile regression suggests (surprisingly) that the income effect on lowering urban poverty is significantly smaller in societies with the highest share of urban people living in poverty. 
Table 4. Cross-sectional quantile regressions of the effects of GDP per capita and urbanization on select urban poverty indicators and rural-urban poverty comparisons.

\begin{tabular}{cccccc}
\hline & $\begin{array}{c}\text { Dependent } \\
\text { Variable }\end{array}$ & Gini Index & $\begin{array}{c}\text { Urban Electricity } \\
\text { Access }\end{array}$ & $\begin{array}{c}\text { Rural-Urban } \\
\text { Electricity Ratio }\end{array}$ & $\begin{array}{c}\text { Urban Poverty } \\
\text { Share }\end{array}$ \\
\hline Quantile/s & & & & \\
\hline GDP per capita & 0.25 & $-0.09^{* *}(0.04)$ & $0.33^{* * *}(0.05)$ & $0.73^{* * *}(0.11)$ & $-0.92^{* * *}(0.13)$ \\
& 0.50 & $-0.10^{* * *}(0.03)$ & $0.19^{* * *}(0.04)$ & $0.70^{* * *}(0.09)$ & $-0.73^{* * *}(0.15)$ \\
Slope equality test & 0.75 & $-0.14^{* * *}(0.04)$ & $0.10^{* * *}(0.04)$ & $0.29^{* *}(0.12)$ & $-0.46^{* * *}(0.17)$ \\
& $0.25,0.50$ & 0.69 & 0.00 & 0.75 & $0.15^{2}$ \\
Urbanization & $0.50,0.75$ & 0.18 & 0.01 & 0.00 & 0.07 \\
& 0.25 & $0.09(0.11)$ & $-0.11^{*}(0.07)$ & $0.33(0.22)$ & $1.09^{* * *}(0.23)$ \\
Slope equality test & 0.50 & $0.08(0.08)$ & $-0.05(0.05)$ & $0.11(0.21)$ & $1.10^{* * *}(0.27)$ \\
& 0.75 & $0.19^{* * *}(0.06)$ & $-0.06(0.05)$ & $0.02(0.19)$ & $0.78^{* *}(0.30)$ \\
Observations & $0.25,0.50$ & 0.91 & 0.24 & 0.27 & 0.95 \\
\hline
\end{tabular}

GDP = gross domestic product. Notes: All variables in natural logs. Sample excludes all countries World Bank-designated as high-income. White-heteroskedasticity-consistent standard errors in parentheses. Statistical significance is indicated by: ${ }^{* *} p<0.01,{ }^{* *} p<0.05$, and ${ }^{*} p<0.1$. For slope equality test, $p$-value shown [16].

\section{Conclusions}

Cities are disproportionately wealthy - a key reason why the world is becoming more urban. Yet, cities are associated with poverty, too. Increases in GDP per capita unambiguously lower poverty and narrow rural-urban gaps. By contrast, levels of urbanization were either unrelated to measures of poverty and rural-urban gaps, or had a nonlinear effect where, initially, increases in urbanization likewise led to improvements in those measures, but at higher levels of urbanization, increases in urbanization exacerbated urban poverty and rural-urban gaps. Thus, this paper, using a broad cross-sectional analysis, has confirmed the results of several regional and single-county studies $[14,19,20]$ that rapid/excessive urbanization can lead to greater poverty and inequality.

Given the tenuous causal relationship between urbanization and economic growth/development $[13,15]$, urbanization policies should be motivated by goals like improving equality (i.e., rural-urban gaps) in health and educational access (and not by encouraging economic growth). How cities are formed likely has an impact on urban poverty and whether rural-urban gaps are reduced or exacerbated. Future work could seek to improve the understanding regarding the potential nonlinear relationships among urbanization and some urban poverty measures and rural-urban differences.

Acknowledgments: A version of this paper was presented at the workshop on Urbanization in Asia: Economics and Social Consequences, held at Seoul, 15-16 December 2016. The author appreciates comments from both the workshop's participants and a reviewer/discussant, as well as financial support from ADBI to attend the workshop. Additionally, comments from the participants of the International Population Conference, Cape Town, South Africa, on 2 November 2017, as well as from anonymous reviewers, helped to improve the final version.

Conflicts of Interest: The author declares no conflict of interest.

\section{References}

1. United Nations. World Urbanization Prospects: The 2014 Revision; United Nations: New York, NY, USA, 2014.

2. Liddle, B. Impact of Population, Age Structure, and Urbanization on Greenhouse Gas Emissions/Energy Consumption: Evidence from Macro-level, Cross-country Analyses. Popul. Environ. 2014, 35, 286-304. [CrossRef]

3. Cobbinah, P.; Erdiaw-Kwasie, M.; Amoateng, P. Rethinking sustainable development within the framework of poverty and urbanization in developing countries. Environ. Dev. 2015, 13, 18-32. [CrossRef]

4. Kuznets, S. Economic Growth and Income Inequality. Am. Econ. Rev. 1955, 45, 1-28.

5. Liddle, B. Urban density and climate change: A STIRPAT analysis using city-level data. J. Transp. Geogr. 2013, 28, 22-29. [CrossRef] 
6. Kenworthy, J.; Laube, F.; Newman, P.; Barter, P.; Raad, T.; Poboon, C.; Guia, B., Jr. An International Sourcebook of Automobile Dependence in Cities, 1960-1990; University Press of Colorado: Boulder, CO, USA, 1999.

7. Kenworthy, J.; Laube, F. The Millennium Cities Database for Sustainable Transport; International Union (Association) for Public Transport (UITP): Brussels, Belgium, 2001.

8. International Union for Public Transport. Mobility in Cities Database; International Union (Association) for Public Transport: Brussels, Belgium, 2005.

9. Redman, C.; Jones, N. The environmental, social, and health dimensions of urban expansion. Popul. Environ. 2005, 26, 505-520. [CrossRef]

10. Fay, M.; Opal, C. Urbanization without Growth. A Not-So-Uncommon Phenomenon; World Bank Policy Research Working Paper WPS 2412; World Bank: Washington, DC, USA, 2000.

11. Bloom, D.; Canning, D.; Fink, G. Urbanization and the wealth of nations. Science 2008, 319, 772-775. [CrossRef] [PubMed]

12. Liddle, B. The energy, economic growth, urbanization nexus across development: Evidence from heterogeneous panel estimates robust to cross-sectional dependence. Energy J. 2013, 34, 223-224. [CrossRef]

13. Liddle, B.; Messinis, G. Which comes First Urbanization or Economic Growth? Evidence from Heterogeneous Panel Causality Tests. Appl. Econ. Lett. 2015, 22, 349-355.

14. Calì, M. Urbanization, Inequality and Economic Growth: Evidence from Indian States; World Bank: Washington, DC, USA, 2009.

15. Henderson, V. Cities and development. J. Reg. Sci. 2010, 50, 515-540. [CrossRef] [PubMed]

16. World Bank. World Development Indicators. Available online: http://databank.worldbank.org/data/ reports.aspx?source=world-development-indicators (accessed on 22 September 2017).

17. Stern, D. Between estimates of the emissions-income elasticity. Ecol. Econ. 2010, 69, 2173-2182. [CrossRef]

18. Wagner, M. The carbon Kuznets curve: A cloudy picture emitted by bad econometrics? Resour. Energy Econ. 2008, 30, 388-408. [CrossRef]

19. Chen, G.; Glasmeier, A.K.; Zhang, M.; Shao, Y. Urbanization and Income Inequality in Post-Reform China: A Causal Analysis Based on Time Series Data. PLoS ONE 2016. [CrossRef] [PubMed]

20. Boadi, K.; Kuitunen, M.; Raheem, K.; Hanninen, K. Urbanisation without development: Environmental and health implications in African cities. Environ. Dev. Sustain. 2005, 7, 465-500. [CrossRef]

21. Koenker, R.; Bassett, G. Regression Quantiles. Econometrica 1978, 46, 33-50. [CrossRef] 